\title{
Aging Workers and the Experience of Job Loss*
}

\author{
Lora A. Phillips Lassus \\ Steven Lopez \\ Vincent J. Roscigno \\ Department of Sociology \\ Ohio State University \\ 238 Townshend Hall \\ Columbus, $\mathrm{OH} 43221$ \\ lassus.1@osu.edu
}

Acknowledgements: This material is based upon work supported by the ASA Fund for the Advancement of the Discipline, and by the National Science Foundation Graduate Research Fellowship Program under Grant No. DGE-0822215. Any opinion, findings, and conclusions or recommendations expressed in this material are those of the authors and do not necessarily reflect the views of the ASA or the National Science Foundation. 


\section{Aging Workers and the Experience of Job Loss}

Aging workers experience the longest unemployment spells of any segment of the labor force and are much more likely than their younger counterparts to drop out of employment entirely. Yet, we still know little about aging workers' struggles to regain employment following job loss. Do they see themselves as structurally disadvantaged? And, what are the consequences for selfperceptions, notions of fairness, and even mental health? We fill this gap by drawing on 52 semistructured qualitative interviews with workers aged 40 to 65 who lost jobs during the Great Recession and have been attempting to find work since. Notable is their keen awareness of both age-specific labor market disadvantages and processes complicating re-employment for all unemployed workers during this period. Respondents articulate sophisticated analyses of how employer biases, credentialism, the job search process, and changes in the economy present very real barriers to reemployment. These perceptions and experiences, our materials suggest, have far-reaching social-psychological consequences, including loss of belief in meritocracy within major institutions; questioning of self-worth; and feelings of loss, isolation, hopelessness and depression - consequences to which stratification scholars should devote more attention, especially since many aging workers become discouraged and eventually drop out of the labor force. 


\section{Aging Workers and the Experience of Job Loss}

Aging workers are disadvantaged. Relative to their younger counterparts, they are more likely to be displaced and, after displacement, remain unemployed for longer (Bendick 1983; Couch 1998). These long-standing patterns were exacerbated by the Great Recession. For instance, between June 2008 and June 2009 the unemployment rate for workers aged 55 and over increased 106 percent, compared to an increase of 70 percent nationally. Additionally, the average duration of unemployment for workers aged 55 and over ballooned to 30 weeks, compared to an average of 22 weeks nationally (Rothenberg and Gardner 2011). Such inequalities, especially when considered alongside the demographic "graying" of the labor force (Bureau of Labor Statistics 2012), are reason for both concern and more scholarly attention.

It is indeed striking how little we know about aging workers' perceptions and experiences during unemployment. Prior work focuses largely on the discrete "bookend events" of unemployment: initial job loss and then eventual reemployment (e.g., Roscigno et al. 2007). There is also a growing literature that examines the material and health consequences of unemployment for aging workers. This literature adopts an employee-oriented approach, often focusing narrowly on particular long-term outcomes (see, e.g., Haider and Stephens 2001; Brand, Levy, and Gallo 2008). Little work to date, however, elucidates efforts toward re-employment between the bookend events. Specifically, it is unclear whether (and, if so, how and with what consequences) aging workers perceive labor market disadvantages. Notable exceptions include the recent work by Sharone (2013) and Gabriel, Gray, and Goregaokar (2010), who analyze the perceptions of all unemployed workers, including those who are aging and higher status. We build on these insights but extend them by considering the experiences, perceptions, and subjective assessments of aging workers across the socioeconomic spectrum. Perceptions and 
subjective assessments are of core importance for scholarly interpretations of inequality (Hirsh and Kornrich 2008; Nielson and Nelson 2005) as well as, possibly, eventual legal rights mobilization (Felstiner, Abel and Sarat 1981; Hirsh and Lyons 2010).

We draw on 52 unique and in-depth qualitative interviews with individuals aged 40 and over who lost jobs since the beginning of the Great Recession and who continue to seek reemployment. These interviews - a subsample from a larger study of job loss experiencesallow us to analyze perceptions of general and age-specific barriers to re-employment, as well as their consequences. Results suggest that unemployed aging workers hold relatively sophisticated views on how employer biases, credentialism, the job search process, and changes in the economy present very real and ongoing barriers. These experiences, in turn, have far-reaching social-psychological implications for belief in meritocracy, sense of self-worth, and feelings of loss, isolation, hopelessness, and depression. Our results offer insight into why aging workers are much more likely to drop out of the labor market, and they inform workplace inequality research more broadly by highlighting less tangible but quite meaningful consequences of job loss.

\section{AGING WORKERS AND UNEMPLOYMENT: CAUSES AND CONSEQUENCES}

It is well-documented that aging workers are more likely than younger workers to become displaced and, on average, experience lengthier job searches (Bendick 1983; Couch 1998; Rothenberg and Gardner 2011). Figure 1 illustrates the percentage of displaced workers by age who were either reemployed, still unemployed, or out of the labor force in January 2012, after becoming displaced during the two prior years. Workers aged 55 and over were much less likely than those under 55 to be reemployed and much more likely to have left the labor force altogether. Collapsing into one category those who are unemployed or out of the labor force 
altogether reveals a notable, age-based inequality: 54 percent of displaced workers aged 55 and older were not reemployed within two years.

\section{[Figure 1 About Here]}

Several structural barriers may be driving these trends. One such barrier is widespread employer abandonment of the traditional social contract, which has allowed market risk to be transferred to employees (Breen 1997; Cappelli 1999). This shift occurred in response to several decades of broad labor market and economic change, and it was facilitated by a contemporaneous decline in employee power (Smith and Rubin 1997; Quadagno 1999; Kalleberg 2009). As a result, job security and stability have declined. This has been especially pronounced for aging workers in once strong but now stagnating or declining occupational sectors (Hutchens 1988; Neumark 2000; Adler and Hilber 2009; Kalleberg 2009).

Discriminatory employer preferences and practices at the individual, occupational, and industry levels may also be partially to blame. Policies and decisions targeted towards aging workers are often influenced by pervasive negative stereotypes about this group (Rosen and Jerdee 1976; Hedge, Borman, and Lammlein 2006; Roscigno 2010), despite widespread evidence that these stereotypes tend to be misperceptions (for reviews see Rhodes 1983 ; $\mathrm{Ng}$ and Feldman 2008; Posthuma and Campion 2009). They are also influenced by the common belief that aging workers cost more in wages and fringe benefits than younger workers do, despite some evidence to the contrary (Schrank and Waring 1989; Rutherglen 1995; Lippmann 2008). Although discrimination against workers aged 40 and over was outlawed by virtue of the Age Discrimination in Employment Act of 1967, it persists throughout the employment process (Loretto and White 2006; Roscigno et al. 2007).

A separate body of literature examines the material and health consequences of these patterns. Materially, reemployed aging workers tend to experience a significant decline in pay 
(Couch 1998; Koeber and Wright 2001; Couch et al. 2009), which persists into the future (Chan and Stevens 2001). Other forms of compensation also decline, including health insurance and pension value (Scott, Berger, and Garen 1995; Couch 1998; Haider and Stephens 2001). Regarding physical health, aging workers who experience job loss face an increased risk of smoking or smoking relapse (Falba et al. 2005), as well as an increased risk of heart attack and stroke within the subsequent decade (Gallo et al. 2006).

Research examining social-psychological consequences of job loss tends to focus on mental health broadly conceived or, most often, depression. Unemployed aging workers experience a substantial decline in mental health, above and beyond that of their younger counterparts (Warr and Jackson 1984; Gallo et al. 2000; Creed and Watson 2003). They also face an increased risk of depression, particularly if the job loss is due to a layoff or blocks the fulfillment of retirement expectations (Brand et al. 2008; Falba, Gallo, and Sindelar 2009). Further, unemployed aging workers face an elevated risk of suicide compared with their younger counterparts (Kposowa 2001). While the discrete experience of job loss contributes to depression, the daily experience of being unemployed is also a major contributing factor (Frese and Mohr 1987).

Prior work has established a strong foundation by uncovering both structural forces driving unemployment trends and associated individual-level consequences. Most studies, however, examine one or the other in isolation, limiting conclusions about the dynamic interplay between the two. Indeed, there is growing consensus that perceptions of structures (independent of their "objective" existence or operation) are consequential for individual well-being and decision-making (Feagin and McKinney 2003; Hirsh and Kornrich 2008; Nielson and Nelson 2005; Roscigno 2007); in turn, systematic differences in mental health and agency reproduce the durable inequalities that exist throughout society (McLeod, Lawler, and Schwalbe 2014). Thus, 
the simultaneous examination of experiences and consequences more completely captures the "macro-to-micro transition" that is occurring (Coleman 1990:19). We accomplish this by drawing on open-ended qualitative interviews conducted during the Great Recession and the extended period of slow economic growth that has followed it.

Equally valuable to our general orientation, outlined above, are more specific and recent streams of work on unemployment. Sharone's (2013) cross-national examination of unemployed workers, for instance, concludes that variability in labor market structures across countries fosters variability in perceptions of the causes of unemployment, as well as repertoires of responses. In the United States case specifically, according to Sharone, perceptions are weighted towards self-blame rather than system-blame. Our analyses address whether Sharone's general arguments about the United States hold for aging workers in particular. Additionally, while Sharone mainly explicates general patterns within each country, our data and the variation by status it affords highlights some heterogeneity in experiences and outcomes - both across individuals and within individuals over time. Recent analyses by Gabriel, Gray, and Goregaokar (2010) explore the consequences of unemployment for aging white-collar workers' self-images and identities. Our data provides the opportunity to extend and evaluate such linkages in general but also across a wider socioeconomic spectrum.

\section{DATA AND METHODS}

This research draws on a larger qualitative study of downward mobility during the Great Recession. The overall sample includes 87 extended, semi-structured interviews with adults who were stably employed prior to losing a job, losing hours, or involuntarily changing fields for a period of at least three months, since the economic downturn began in 2007. For the purposes of this study, we restricted the sample to those aged 40 or over. This conforms to the definition of 
aging workers as a protected group set forth within the Age Discrimination in Employment Act, which is the key legislation protecting aging workers in the United States (ADEA 2013). The sample was also restricted to respondents who lost a job, in order to isolate the experience of unemployment. The final sample, after restrictions are applied, consists of 52 interviews. These interviews ranged in length from half an hour to three-and-a-half hours, with most interviews lasting one to one-and-a-half hours.

Recruitment of respondents was pursued through a variety of channels, including job fairs, trade unions, churches, immigrant organizations, networking groups, nonprofit organizations serving in-need populations, resource fairs, and public online resume sites, all within the Columbus, Ohio, area. Potential respondents were approached by a member of the research team and given a brief description of the study. Then, those who fit the study criteria and were interested in participating were asked for their contact information for later scheduling. Immediately following, they were informed they would be compensated 30 dollars upon completing an interview. Respondents were made aware of this incentive during recruitment because some respondents' precarious financial situations may have limited their ability to travel for and participate in an uncompensated interview. At the same time, leaving the incentive unstated until the respondent was determined to be qualified and interested lessened the motivation for dishonesty and potential for feeling coerced.

Interviews typically took place in private conference rooms reserved at local public libraries, although a small number were completed elsewhere or over the phone. All interviews were audio recorded. Given the semi-structured, open-ended nature of the interviews, researchers were instructed to prompt respondents in uniform ways across a broad range of pre-determined topics; however, interviews were not conducted using a detailed interview guide with specific, sequential questions. This format ensured consistency and direction while allowing researchers 
to explore important topics and themes that emerged during particular interviews. Topics covered during every interview included background; job loss information; and the financial, attitudinal, behavioral, and relational changes that occurred after the job loss and during the job search process. The breadth and depth of these questions allowed interviews to move beyond the commonsense financial consequences of unemployment, uncovering a much wider range of consequences for workers.

Respondents were selected with a high level of attention to diversity — a point that differentiates our analysis from Gabriel, Gray, and Goregaokar (2010). The composition of the sample is summarized in Table 1 . In terms of gender, there are roughly equal numbers of males and females. Racially, blacks are overrepresented. Finally, occupationally, respondents were coded based on the Equal Employment Opportunity Commission’s nine-category job classification scheme. These codes were then collapsed into three categories, based on typical worker attributes and returns to working: management and professional, skilled manual, and lowwage service. Most respondents fall in the highest and lowest occupational categories, with a small number of respondents falling in the middle. This is consistent with national shifts in the distribution of industries and occupations over the past several decades (Quadagno 1999; Kalleberg 2009). Overall, the sample reflects a research strategy aimed not at representative sampling but, rather, toward a sample sufficiently diverse to allow for qualitative comparisons across groups. Thus, instead of attempting to draw statistical inferences about a population based on patterns in a sample, our approach allows us to explore important dimensions of peoples' experiences that are difficult or impossible to quantify or to capture in survey research.

Our analysis consists of in-depth qualitative immersion utilizing complete transcriptions of the audio files. In particular, a coding device was iteratively developed based on interplay between theory and data. Theory and previous literature suggest numerous themes that were 
ultimately borne out in our data, including self-blame and depression; however, a handful of theoretically driven themes turned out to be less applicable. Most prominently, this includes strategic self-presentation to potential employers, such as deleting a master's degree from a resume to avoid appearing overqualified. At the same time, an initial read-through of transcripts uncovered several emergent themes that could not be neatly subsumed under existing themes. These included historical changes to the job search process and isolation. Once the coding device was finalized, transcriptions were re-read and systematically coded utilizing the device. The quotes we report below reflect emergent patterns that traverse the reflections of interviewees.

[Table 1 About Here]

\section{LABOR MARKET PERCEPTIONS}

Prior research on structural barriers at the discrete points of job loss and reemployment makes clear the labor market disadvantage experienced at these bookend events of unemployment. We do not know enough, however, about aging workers' perceptions of the labor market during the extended period of slow economic growth and depressed employment that has characterized the “jobless recovery” following the Great Recession, let alone about aging workers' perceptions of their labor market disadvantage. Our analyses help address these questions, revealing that 80 percent of respondents recognize some kind of structural labor-market barrier to their own reemployment. Some of the barriers respondents discussed, such as age discrimination and credentialism, are seen as uniquely affecting them given their age. Other barriers, such as recent changes to the job search process and the ongoing depressed economy, reflect perceptions of a broadly unfavorable labor market for all workers. 


\section{Age Discrimination}

Employer preference for hiring younger workers is one structural barrier clearly cited by our respondents - particularly (though not exclusively) those aged 55 and older. Although it is illegal to ask an applicant's age, several respondents note that employers have developed creative ways of finding out. Andrew, a former corporate salesperson, describes one strategy as follows:

One thing that I couldn't understand is, I started online looking into jobs and I find one that I want to apply to. And I work my way down, all the information and everything. Even though the federal government says you can't ask age, if you ask the year they graduated from high school, do the math. Add 42 on to that, you've got today. I was born in 1952, graduated in

1970. You know, 42 and 18, add it up it's usually 60 . And so it's a joke on some of this stuff.

As Andrew notes, if an employer is allowed to ask the year of high school graduation, they can readily identify and discriminate against aging applicants without directly asking for their age.

Even when discrimination does not prevent aging applicants from securing an interview, it nonetheless often plays centrally in conversations with potential employers. Many of our respondents describe feeling a need to defend themselves in such situations and were occasionally illegally forced to do so by potential employers. Joe, a 59-year-old veteran and former automobile salesperson, lost his job when the car company he worked for folded at the beginning of the recession. He recounts from memory a subsequent interview that he had with a human resources manager, after applying for a telemarketing position.

HR: Do you realize that you're almost out of buckets?

Joe: Excuse me?

HR: Do you realize you're almost out of buckets?

Joe: Buckets? You mean a bucket, like for mopping the floor? A bucket with water?"

HR: Yeah. Do you know what I'm talking about?

Joe: No....

HR: If this were a bucket, you'd have four buckets in your life. Your first bucket was in your employment from when you were 20 to 30 . Your second bucket was when you were 30 to 40 . Your third bucket was when you were 40 to 50 . You're in your last bucket, 50 to 60 . You've got a little over two years left before your buckets are complete.

Joe: Are you serious?

HR: I'm very serious. You're just about out of buckets. 
Joe: You know, in the position that I'm applying for that has to do with a telephone, no one is going to see me on the other end of a telephone, and I'm applying for a career position.

HR: Are you aware of what the Y2K generation is?

Joe: No.

HR: You're gonna be working with people who are 25 years old, and you're probably going to come in and you're probably going to do a good job, and they're gonna resent you every day, and they're not gonna want you here.

Throughout the interview, Joe revisited this story several times, describing how the

experience had seeped into his perception of himself, diminishing his confidence that

reemployment was in sight. But what incentive do employers have to find out this information?

According to many respondents, employers believe it benefits their bottom line. This perspective

is articulated by Colleen, a 44-year-old former marketing and visual communications

professional. She notes:

I'm over 40. And even though my position specifically was eliminated entirely, you could hire someone fresh out of college and pay them a lot less than what I was making. And that's one of the things I look at in my job search and think it doesn't bode well for me. Even though I'm willing to take a job at a lower rate, it's harder for me. I'm having a hard time getting people to even have that conversation with me.

Colleen's statement echoes what many respondents brought up: that employers typically associate age with higher pay, which is a cost they are often unwilling to assume when lowercost options are available. Additionally, Colleen makes it clear that she is willing to accept lower pay simply for the opportunity to reenter the labor force. She is not alone in the sentiment. Indeed, nearly all respondents who cite employer cost concerns specifically state that they will work for less than employers believe. This suggests that aging workers do not actually maintain reservation wages that are too high, placing their labor market disadvantage even more squarely in the structural, employer-driven realm.

Other potential preferences for youth emerged throughout the interviews, all of which related to the negative ageist stereotypes that pervade our culture. These include the view that aging workers terminate employment at a company more rapidly than younger workers, that they 
are less dedicated, and that they possess diminished mental capabilities. Across the board, those interviewed reject these stereotypes and express frustration about their persistence. For instance Tyler, a 62-year-old former entrepreneur and upper-level manager, says:

If you're equal on paper and one of them is sixty-two and the other one is twenty-eight, which one do you hire? There's a bias. There's nothing you can do, and I understand it. But the thing is though, that it's bad judgment. 'Cause here I am at sixty-two-I'm in bad enough financial shape that I know I'm never going to retire. So they can probably get another eight or ten years out of me, and I just would really like the stability. That guy that they hire that's twenty-eight is only going to stay two years and job-hop, so it's a better decision to hire me. But how do I convey something like that?

Tyler and others recognize that such biases pose a significant barrier to reemployment. Although they uniformly reject negative stereotypes and generally believe the opposite to be true, respondents often feel unable to adequately express these sentiments on applications or during interviews. For white male respondents this is often their first experience with discrimination, while respondents who belong to at least one minority group cite age as one of the several traits that employers illegally use.

\section{Credentialism}

Related to outright discrimination is the distinct issue of credentialism. Many of our respondents recognize that employers today prefer workers with college degrees and specific, extensive skillsets, even when hiring for positions that have not traditionally required these. While employers increasingly view credentials as essential for performance, aging workers are less

likely than younger workers to possess such credentials (Sandell 1987; Hanisch 1999; Taylor and Geldhauser 2007; Lippmann 2008).

Ian, a 40-year-old former architectural drafter, says: "Here I am without a degree trying to make it, and despite my experience and my skill level it wasn't enough. People like to see that little piece of paper, you know?" Ian believes that he possesses all the abilities necessary to 
successfully perform his job, thanks to years of on-the-job training and experience. Nonetheless, employers were unwilling to consider his application, preferring to look at applicants with a college degree but, perhaps, less experience doing the job. As a result, Ian returned to school to obtain a college degree.

Sometimes the preference for a college degree goes beyond individual employers, having been integrated into an entire occupation over time. This poses significant challenges for individuals who entered the field before current credential standards were in place. Courtney, a 59-year-old former social worker, had this experience. She explains:

I decided to go back to school to get my license because . . . back in the day you didn't need nothing ... to do social work. Now they upgraded everything, so now you got to reinvent yourself and get more education. So, the jobs that I was getting, I have to now be licensed to perform that same position.

An increase in credentialing over time pushed Courtney out of the field that she was working in for years. Much like what happened to Ian, there was no credit for her years of experience. Either she met the new standard, or she would never again work in that field.

Although returning to school seems like a simple, straightforward solution to the problem of credentialing, doing so is not always possible or beneficial for unemployed aging workers. Indeed, aging workers often have unavoidable personal or financial obligations that have accumulated during their journey through the life course. Additionally, they have less incentive to make costly investments in themselves since they have fewer working years left to recoup the investment (Bartel and Sicherman 1993; Blundell et al. 1999; Friedberg 1999). More education may even be detrimental for aging workers, who tend to experience longer bouts of unemployment the more education they have (Katz 1974). 


\section{It's an Online World Now: Job Searching on the Internet}

The shift from filling out paper applications - often in person - to applying online is identified as disadvantageous for all job seekers. As aging workers with more years of experience in the labor market, however, our respondents may be more likely than younger workers to notice this change and/or to perceive it as a disadvantage. As Frank, a 60-year-old former banker, explains

Today's world, number one you can't walk into a place and apply for a job no more. It's all internet-based anyway. So if you think about that: when you send in your resume, probably 1,000 other people are sending them in. So this guy's got this pile of resumes that came through the Internet because people are coming from all over. And so you need to stand out from that. And they go through it and divide out who's who. And so how do you make yourself stand out? And how do you really compete because, to me, getting in front of somebody and talking to them, you can really see the value they add. It's not going to be what's on that piece of paper anyway. We've taken that out of our life to hire people.

Early in his career, Frank had experienced an in-person application process where his interpersonal skills bolstered what employers saw on paper in his application and resume.

Changes to the process, though, have made applying more time-consuming, employer-specific, frustrating, and impersonal. While our respondents uniformly perceive the new job search process as inferior to the old one, this sentiment is especially pronounced among white-collar workers. It influences respondents' expectations about reemployment and, correspondingly, a host of social-psychological outcomes.

It is worth noting that the majority of respondents are highly computer literate, owning their own computers and using computers in the workplace for many years. Thus, the barrier is not that their skills failed to keep up with technology but, rather, that the current process is less conducive to gaining the attention of employers. According to Leah, a former accounting manager in her 50s:

It just seems to me that they have made it harder for the applicant. They're trying to make it easier for the company, but they've made it harder for the applicant. . . . I can at least work through [the online application] because I've been doing it for 25 to 30 years, and 
I've had to learn how to navigate through different types of software.... They're trying to make it easy, but not necessarily for the applicant. That is my conclusion.

Leah and others feel competent to use computers and apply online. Rather than lacking the necessary skills, the respondents believe that the current job-seeking process benefits employers more than applicants and that reemployment is consequently more difficult than in the past.

\section{It's Hard for Everyone These Days: Searching for a Job in a Bad Economy}

Finally, a majority of our respondents identify general economic restructuring processes as barriers facing all workers. One such set of processes includes neoliberal shifts that have accompanied globalization, de-industrialization, and outsourcing. The comments of Sally, a 50year-old former custodial worker whose job was outsourced three times (!), are typical in this regard:

And this economy - I always still say 'Bring it back to America. Quit going overseas.' We had a shoe factory downtown that made house slippers and shoes and stuff. Who knows where that company went, you know? ... They need to bring back the motor companies and stuff. Quit shipping all that overseas.

Sally and others expressing these views feel that policy-driven structural changes, such as globalization and outsourcing, are disadvantaging American workers as a whole. The consequence, for them, is difficulty reentering the labor force once unemployed.

Another problem respondents identified centers on automation and technology. Natasha is a 40-year-old former customer service and claims processing associate, who is currently working part-time as a food demonstrator within a local grocery chain. Reflecting upon the sign language interpreting certification that she received years ago, she says:

The interpreting thing, that's just basically contract to contract, so I know I wouldn't be able to do [that] for the rest of my life. So that's why I opted out and did customer service. But I didn't really think about — when you had the automated systems and the computers and the technology, which is basically messin' up all those manufacturing, customer service, retail, what have you. Technology is basically just taking over these jobs. You 
know, I mean pretty soon it's gonna be-you're not gonna need a janitor because you have a Roomba that can vacuum and mop a floor. They're gonna get to the point where they're gonna have a robot dusting and what have you. So they're gonna be eliminating a lot of jobs, basically for people.

According to Natasha, the fast pace of technological change, combined with employers' desire to cut costs wherever possible, placed employees in an increasingly precarious position over the last several decades. She also notes how jobs that previously seemed immune to automation had become automated. Looking into the future, she predicts that this trend will continue, rendering more and more workers obsolete.

In sum, most of our respondents recognize multiple structural barriers to their own reemployment. Employer discrimination against aging workers and the effects of credentialism are highly salient, but many also perceive broader labor market and economic changes as disadvantageous for all job seekers. Importantly, they do not simply deflect blame for their situation onto external factors. Despite their keen awareness of structural barriers, many also individualized their situation, a point recently made by Sharone (2013) and that may be especially salient in the U.S. case.

\section{SOCIAL PSYCHOLOGICAL CONSEQUENCES}

In becoming unemployed, aging workers experience a significant disruption to the normative life course - a disruption exacerbated by structural barriers to reemployment. Our respondents' lives prior to unemployment had been characterized by stable work, and many were looking towards retirement in the not-too-distant future. After the job loss event, though, they found themselves in a twilight zone between work and retirement. Not surprisingly, most struggled to make sense of their situation, with 94 percent recording at least one negative social-psychological consequence. Several common consequences warranting elaboration emerged: loss of trust in the 
traditional social contract of employment, reflection upon and questioning of identity, and isolation and depression.

\section{Loss of Trust}

Reflecting upon the labor market and economic changes that operate as barriers to reemployment, many respondents note a loss of trust in the traditional social contract of employment, which they were socialized under. Although some had already lost this trust after weathering several decades of labor market and economic changes, some were previously sheltered from these changes by their long-term, stable employment with a single company. In the past - at least prior to losing their jobs - many firmly believed that their loyalty begot loyalty on the part of employers. They also invested heavily in the idea that hard work led to employment security. Their job loss and current search process forced them to question these assumptions and, for many respondents, change their entire worldview. This is the case for

Frank, the former banker, who notes:

It's interesting that my father worked 30 years in a factory, retired. And they always talked to us about longevity, staying with the same employer, and being loyal to-I think, you know, one of the things I learned is there's no loyalty. ... You talk about loyalty, and doing the right things, and doing what's asked of you. And you do that, you know? You kind of feel like, well, it doesn't really mean anything. And you don't know in your next job what you could do different that would put you in a position where it's not you. That, to me, was the biggest - that was the hardest part, because I didn't know - okay what did I do here? ... You go through everything and see if there's anything in there that maybe would tell you something, and there was nothing there.

Frank was socialized under the old social contract of employment by his parents and had tried to build his career with such terms in mind. Now, however, he believes employers betrayed this pact, resulting in a lost sense of control and uncertatin career trajectory. At the time of our interview, he was struggling to understand what this means for his future. 
Some respondents successfully came to terms with the disappearance of the traditional social contract of employment. Their opinions of this change, however, remain firmly critical. This is perhaps not surprising given broader workplace transformations they have seen over time. One such respondent is Andrew, the former corporate salesperson. According to Andrew:

The American dream is - that's out the window. The American dream-you work for your company for 40 years, get the gold watch at retirement, and you can go out and travel and your house is paid off - that's gone in this country. It's not coming back, no matter what. Everybody's trying to put a good spin on it, but it's not coming back. Unfortunately, that's the way it's become, and you're stuck with it. . . You never expected that since 2008, three or four million people would lose their house. Not in America. This country has gotten more worried about everybody else in the world than it has its own people.

For Andrew and others, their unemployment experience rewrote their understanding of the social contract of employment. Given the strong linkage for many between the traditional contract and cultural notions of the American Dream, a number of respondents feel let down and expend a great deal of mental and emotional energy coping with the loss of trust and trying to reformulate their conceptions of work and opportunity in America. Overall, these sentiments are most common among respondents who are unemployed for longer than six months, white-collar, female, or married.

\section{Identity}

Experiencing an unexpected life course disruption encouraged many respondents to reflect upon and question their own sense of identity. For some, there is a strong link between identity and profession. As such, job loss has left them uncertain about who they are and about their purpose in life. Such is the case with Stella, a 46-year-old former accountant.

"I guess I've always been considered to be an accountant. I mean my ex-husband- that was always his joke. 'Talk to the accountant, she's got all the money.' I've always been the responsible one and now it - it makes me feel a little less- how do you want to put it? ... Less of a person." 
Stella and others desire to maintain their professional identity, but unemployment makes them feel unable to do so. As a result, they struggle to define who they now are as individuals.

On the other hand, some respondents' personal and professional identities had long been discordant. In such cases, unemployment opens a window of opportunity for bringing professional identity in line with personal identity. Respondents in this camp express enthusiasm about the opportunity to obtain a job that better suits their wants and needs. According to Charlie, a 49-year-old former security guard, "I've decided I'm gonna find some way to market [my photos] and make some money off of it, 'cause I've just absolutely enjoyed myself immensely doing this." Charlie and others are excited and optimistic about the opportunity to branch out and try something new. Notably, though, very few respondents had successfully transitioned to a new career.

Respondents' reflection upon and questioning of their identities also emerges in statements related to self-image. One of the most pervasive sentiments that respondents express is that of shame. William, a 42-year-old former graphic designer, is clear about this aspect of his unemployment experience. "I definitely felt shame. I think I feel more shame because of the length of this." Thus, William, like many other respondents, is ashamed of his unemployment. For him, this feeling of shame is significantly shaped by the labor market disadvantage that he faces, which had kept him out of the labor force for approximately two years at the time of the interview.

For many of the married men who were interviewed, this sense of shame is partially linked to their roles as husband and father. These men believe they are failing to fulfill their duty as family provider. This is the case for Rambo, a 54-year-old former salesperson.

"I'm afraid I'm not gonna be able to provide for my family, and I find some shame in that, you know? I mean, there's that level too. As a guy I just want to be a provider. I wanna help 
my family, especially being older than my children. And I don't know how long I'll be here, you know?"

Echoing what other married men express, Rambo shares his sense of shame over not being the provider that he feels he should be. The result is a daily struggle to manage the blow to his selfimage.

For several respondents, a loss in confidence is clear. Edna, a 56-year-old former on-air personality for public news and radio, expresses this loss of confidence. According to her "I think that's the worst thing: that being unemployed has intimidated me. And I was never intimidated on that level. I mean, of course I've been intimidated, but not about work. And I think that I actually became afraid of the workforce, and there's nothing to be afraid of." Edna's loss of confidence is shaped substantially by her labor market disadvantage, having been unemployed for several years following a very successful career.

For most respondents, though, self-doubt goes beyond a loss of confidence. These unemployed aging workers often blame themselves for their unemployment situation. Sometimes this takes the form of questioning their job search process. William, the former graphic designer, noted "You're always constantly asking yourself—especially when you're in my position—'Am I doing enough? Am I doing the best? Am I doing enough?’” Despite many respondents' awareness of the barriers to reemployment that they face, blame for failing to find reemployment is all too often directed primarily at themselves.

The respondents also express doubt over their skills and qualifications, something which lends itself to more self-blame. Most often, this doubt is linked to perceived credentialism by employers. Mark, a 57-year-old former IT professional, comments “I don't have a bachelor's degree. There are some of these places that will go 'Well, you have a bachelor's degree, don't you?' Uh, no. I have thirty years' experience. Which is another thing I'm trying to do right now, 
which is trying to go back and button that gap." Like Mark, many respondents blame themselves for their (lack of) educational history. Although they widely believe that their extensive experience makes them highly qualified for most jobs, a perception of structural disadvantage encourages returning to school. In doing so, the respondents believe they will update their skills and make themselves more marketable to potential employers.

Self-doubt is not always confined to the present. Indeed, many respondents express regret about past decisions that they believe contribute to their situation and negatively impact their chances for reemployment. This is the sentiment felt by Stella, the former accountant. She reflects that:

I think that's a lot of my downfall, because I started working at the accounting firm in 1986, right out of college. I got my two-year [degree] then moved to Columbus. I accepted this job. If I would have been out there and looked a little harder I might have found a better job making more money, and by the time my 20 years rolled around I would have been making a lot more money and been working for a better company.

Stella regrets decisions that she made early in her career. She, like others, believes that she would be in a different position now had she made different decisions years ago. For some respondents these past decisions are employment-related, whereas for others they are educationrelated or related to decisions about where to live. Whatever the nature of the regret, it adds up to self-doubt that respondents struggle with on a daily basis.

Shame and self-doubt are by no means the only sentiments with pertinence for selfimage. A number of our unemployed aging workers also struggle with feelings of pride. For Emily, a 41-year-old former insurance broker, life is a constant struggle between maintaining some sense of pride and not letting pride hinder her success. She notes:

I would say everybody I've spoken with, they know that I don't have a job. And they know that I'm struggling, from the standpoint of not having an income. They're all willing to help. Through word of mouth or me telling them, everybody knows. You just don't know where that break's gonna be - somebody knowing somebody. So, I'm pretty open about it. Now, my weakness is asking for help. 
For a number of respondents, including Emily, pride is something that can provide a pathway to reemployment. At the same time, it can also hold one back. Striking the correct balance of pride and humility is a constant challenge.

Not all of the self-image related sentiments that respondents express are negative. One emergent positive feeling is strength. A small number of respondents had not realized how strong they are until faced with unemployment as an aging worker. One such respondent is Emma, a 50year-old former risk and compliance manager in the public sector. According to Emma "I'm stronger personally. ... I know, now that I've experienced it, if it ever happens again, I know I can handle it. I know that I will live. I know that I'm not dead. I know that it's not hopeless." For her, one of the unexpected positive outcomes of becoming unemployed is gaining strength and learning that she can overcome adversity. Although she sometimes struggles to maintain this attitude, Emma believes that it helps her a great deal in coping with her situation.

\section{Isolation and Depression}

Finding themselves in the twilight zone between work and retirement, our respondents have clearly begun individual journeys of order restoration and sense making to cope with their life course disruption. Reflecting upon themselves and the world around them, many have developed intertwined feelings of isolation and depression. This isolation and depression has two distinct sources: the material hardship of unemployment and the experience of unemployment more generally. For many, the material hardship of unemployment stands in stark contrast to the comfort they grew accustomed to through long-term, stable employment. This is the case for Sally, the former custodial worker. She says:

It's kinda sad and depressing to a point where, okay you can't go out and have your fun without seeing how much money you have in your checking account and things. But I'm 
doing alright. I didn't get the blues or anything, but I did get depressed sometimes. Because I go to the grocery store and it's like, 'Okay, how much should I spend on groceries?' So I would write out exactly what I need and not buy extras.

Sally and other unemployed aging workers spent decades becoming settled into a certain level of material comfort. Given their long duration of stable employment, learning to scale back is especially challenging and, oftentimes, depressing. Other respondents similarly suffer from isolation and depression as a result of the material hardship of unemployment, but their sentiments stem from lost relationships. This is the case for Jim, a 59-year-old former banker. According to Jim,

Surprisingly, some of the folks that we felt were pretty good friends, it turned out that they were friends because we could socially do things. And so that's been a little bit disappointing. Since we can't go to all those types of events, certain folks just don't have the same level of interest in just keeping in touch, and that's been a little disturbing. And we do understand that happens. Again, there are times through the course of the day or the week or the month that you allow yourself to feel sorry for yourself, as much as you try not to.

Jim established many friendships over the years where the primary activity was dining out or attending cultural events. He was able to do these things thanks to his previous income, which had been stable across many years. Although Jim desires to maintain these relationships now that he is unemployed, his former friends feel less willing or able to do so. This leaves him and others disappointed, isolated and, at times, depressed.

Many respondents also feel isolated and depressed as a result of the unemployment experience in general. Beyond the material hardship they face, these respondents are accustomed to being employed, having their skills in demand, and feeling independent. According to Emma, the former risk and compliance manager,

It's lonely when you find yourself at home when everybody else is out doing their thing. I mean, everybody else is at work, everybody else is at school, and you're stuck on a computer looking at a maze of what appear to be opportunities, very few of which fit what you need, or you fit their needs or meet their needs or whatever. 
Emma and others struggle with being home all day, every day after decades of full-time work. They had consistently experienced a certain level of social interaction and affirmation, which is now missing from their lives. At the same time, the job search process fills the void with pervasive isolation, challenges, and disappointments. The result is some level of isolation and depression. For some respondents, it is severe. This is the case for Terry, a 44-year-old former welder, who says:

No I'm just barely doing it by a thread, because I know I graduate Friday. But if I had to do this like six or seven months I wouldn't, 'cause I don't - I just sit in a room. I stay on the eighth floor, so I have a good view of all downtown. I can just look out my window and see everybody walking down. I just be looking and staring out my window, hating - wishing I had a good job or a car like these people got. Feeling sorry for myself and just, you know, won't bathe, won't get up, won't do nothing — just lay there.

Sadly, Terry is not the only respondent to express this level of isolation and depression.

Some respondents echo her sentiments, describing trouble getting going each day. Several experience such strong and unmanageable feelings that they seek out professional help, ultimately being prescribed anti-depressant medication. Many have no history of mental illness. Unemployment has simply shaken them to the core.

Indeed, these respondents have experienced a disruption to the normative life course. This disruption is a consequence of structural barriers and ageist exclusions. It should thus come as little surprise that, for many, the end result is shaken trust in the traditional social contract of employment, uncertainty over their own sense of identity, and isolation and depression.

\section{DISCUSSION AND CONCLUSION}

Prior research has offered leverage for understanding the structural barriers aging workers face when it comes to job loss as well specific, most often material consequences. Significantly less is known, however, about the struggle for reemployment, aging workers' awareness and 
perceptions of the structural barriers they face, the full range of social-psychological consequences that manifest during unemployment, and whether/how these affect sense-making, social-psychological well-being, and repertoires of responses. In this article, we draw from 52 indepth qualitative interviews with aging workers who became unemployed since the beginning of the Great Recession in an effort to provide insight on these matters.

We find that unemployed aging workers indeed recognize structural barriers to their own reemployment; namely, employer discrimination, credentialism, the job search process, and economic changes. We also identify three important social-psychological consequences: loss of trust in the traditional social contract of employment, reflection upon and questioning of identity, and the intertwined feelings of isolation and depression. Frequently, these social-psychological consequences are shaped by the structural barriers to reemployment faced by aging workers, influencing respondents' experiences in the twilight zone between work and retirement and, in turn, reinforcing structural inequalities.

Our findings confirm but extend those of Sharone (2013) and Gabriel, Gray, and Goregaokar (2010) in important ways. In particular, Sharone's conclusion that unemployed workers in the United States engage predominantly in self-blame holds true for unemployed aging workers specifically. However, our data paint a more nuanced picture, wherein self-blame is tempered by keen awareness of structural barriers. Further, building on Gabriel, Gray, and Goregaokar, particular perceptions and consequences indeed appear linked. Nonetheless, our data demonstrate that the incidence of both particular perceptions and particular consequences may vary in unique ways depending on an individuals' status (i.e., socioeconomic, gender, race).

As with any research, our design and analysis decisions strengthened conclusions in certain ways while limiting the scope of what we could address in others. These limitations provide fruitful avenues for future research. We hope to pursue these avenues ourselves, and we 
hope other scholars will follow suit as well. First, by focusing explicitly on age we have limited our discussion of potential within-group heterogeneity along various other social cleavages. Second, by interviewing individuals who are currently unemployed and seeking reemployment we are unable to assess the longer-term repercussions of late-life job loss. Specifically, it is unknown whether the perceptions and consequences identified here persist after unemployment is resolved. Finally, since the bulk of our interviews were with aging workers who were still in the labor force (i.e., seeking reemployment) rather than those who had exited, we are left to speculate on the extent to which the processes outlined force eventual labor market withdrawal. Future qualitative strategies focusing specifically on those who are now altogether out of the labor market would certainly offer such elaboration.

As the American labor force ages it is increasingly important to understand the situation facing aging workers. This is especially true given this group's growing vulnerabilities in unemployment, longer unemployment spells, and higher incidence of labor market withdrawal (Bendick 1983; Couch 1998; Rothenberg and Gardner 2011). By addressing these vulnerabilities specifically and the experiences of unemployed aging workers generally, our analyses contribute to the work, stratification, and social gerontology literatures in several ways. First, we make age central to our analyses. Age, we believe, deserves the same level of scholarly attention as the more traditional social cleavages of race, class, and gender.

Second, we focus on individuals who are currently unemployed rather than those who have experienced unemployment in the past. This offers significant leverage for gauging the breadth and depth of perceptions and experiences, free from the biases and memory attrition that may result from retrospection. Moreover, it helps fill in a "black box" within workplace stratification research, shedding light on the processes that occur between the bookend events of unemployment (i.e., job loss and reemployment). 
Finally, our analytic strategy and findings highlight what we believe to an imperative for future scholarship; namely, to unearth and elaborate upon the human costs of exclusion and unemployment above and beyond more tangible material indicators that emerge at a single unit of analysis. Indeed, the laudable focus of much work stratification literature is on arguably more easily quantified outcomes. Yet, these are hardly the only outcomes scholars should be mindful of. Rather, we situate ourselves within an emerging group of scholars (e.g., Gabriel, Gray, and Goregaokar 2010; McLeod, Lawler, and Schwalbe 2014; Sharone 2013) whose work emphasizes the need to think more broadly about stratification process and outcomes-particularly those processes and outcomes that are highly meaningful, albeit often more challenging to measure. 


\section{References}

Adler, Geri and Don Hilber. 2009. "Industry Hiring Patterns of Older Workers." Research on Aging 31(1):69-88.

Age Discrimination in Employment Act of 1967, 29 U.S.C. $§ 621$ et seq. Retrieved July 7, 2013 (http://www.eeoc.gov/laws/statutes/adea.cfm).

Bartel, Ann P. and Nachum Sicherman. 1993. "Technological Change and Retirement Decisions of Older Workers." Journal of Labor Economics 11(1):162-183.

Bendick, Marc, Jr. 1983. "The Role of Public Programs and Private Markets in Reemploying Displaced Workers." Policy Studies Review 2:715-733.

Blundell, Richard, Lorraine Dearden, Costas Meghir, and Barbara Sianesi. 1999. "Human Capital Investment: The Returns from Education and Training to the Individual, the Firm, and the Economy." Fiscal Studies 20(1):1-23.

Brand, Jennie E., Becca R. Levy, and William T. Gallo. 2008. "Effects of Layoffs and Plant Closings on Subsequent Depression Among Older Workers." Research on Aging 30(6):701-721.

Breen, Richard. 1997. "Risk, Recommodification and Stratification.” Sociology 31(3):473-489.

Cappelli, P. The new deal at work: Managing the market-driven workforce. Boston, MA: Harvard Business School Press, 1999.

Chan, Sewin and Ann Huff Stephens. 2001. "Job Loss and Employment Patterns of Older Workers." Journal of Labor Economics 19(2):484-521.

Coleman, James S. 1990. Foundations of Social Theory. Cambridge, MA: Harvard University Press.

Couch, Kenneth A. 1998. "Late Life Job Displacement.” The Gerontologist 38(1):1-17.

Couch, Kenneth A., Nicholas A. Jolly, and Dana W. Placzek. 2009. "Earning Losses of Older Displaced Workers: A Detailed Analysis with Administrative Data." Research on Aging 31(1):17-40.

Creed, Peter A., and Tania Watson. 2003. "Age, Gender, Psychological Wellbeing and the Impact of Losing the Latent and Manifest Benefits of Employment in Unemployed People." Australian Journal of Psychology 55(2):95-103. 
Falba, Tracy, William T. Gallo, and Jody L. Sindelar. 2009. "Work Expectations, Realizations, and Depression in Older Workers." Journal of Mental Health Policy and Economics 12(4):175-186.

Falba, Tracy, Hsun-Mei Teng, Jody L. Sindelar, and William T. Gallo. 2005. "The Effect of Involuntary Job Loss on Smoking Intensity and Relapse." Addiction 100:1330-1339.

Feagin, Joe R. and Karyn D. McKinney. 2003. The Many Costs of Racism. Lanham, MD: Rowman \& Littlefield.

Felstiner, William L., Richard Abel and Austin Sarat. 1981. "The Emergence and Transformation of Disputes: Naming, Blaming, Claiming..." Law and Society Review 15(3/4):631-54.

Frese, Michael and Gisela Mohr. 1987. "Prolonged Unemployment and Depression in Older Workers: A Longitudinal Study of Intervening Variables." Social Science \& Medicine 25(2):173-178.

Friedberg, Leora. 1999. "The Impact of Technological Change on Older Workers: Evidence from Data on Computers.” Discussion Paper 99-11, University of California, San Diego, Department of Economics, San Diego, CA.

Gabriel, Yiannis, David E. Gray, and Harshita Goregaokar. 2010. "Temporary Derailment or the End of the Line? Managers Coping with Unemployment at 50." Organization Studies 31(12):1687-1712.

Gallo, William T., Elizabeth H. Bradley, Michele Siegel, and Stanislav V. Kasl. 2000. "Health Effects of Involuntary Job Loss Among Older Workers: Findings from the Health and Retirement Survey.” Journal of Gerontology 55B(3):S131-S140.

Gallo, William T., Hsun-Mei Teng, Tracy A. Falba, Stanislav V. Kasl, Harlan M. Krumholz, and Elizabeth H. Bradley. 2006. "The Impact of Late Career Job Loss on Myocardial Infarction and Stroke: A 10 Year Follow up Using the Health and Retirement Survey." Occupational and Environmental Medicine 63(10):683-687.

Haider, Steven J. and Melvin Stephens, Jr. 2001. "The Impact of Displacement on Older Workers." Working Paper Series 01-13, Report No. DRU-2631-NIA. RAND, Santa Monica, CA.

Hedge, Jerry W., Walter C. Borman, and Steven E. Lammlein 2006. The Aging Workforce: Realities, Myths, and Implications for Organizations. Washington, D.C.: American Psychological Association.

Hirsh, C. Elizabeth, and Sabino Kornrich. 2008. "The Context of Discrimination: WorkplaceConditions, Institutional Environments, and Sex and Race Discrimination Charges." American Journal of Sociology 113(5): 1394-432. 
Hirsh, C. Elizabeth, and Christopher Lyons. 2010. "Perceiving Discrimination on the Job: Legal Consciousness, Workplace Context, and the Construction of Race Discrimination." Law and Society Review 44(2):269-98.

Hutchens, Robert M. 1988. "Do Job Opportunities Decline with Age?” Industrial \& Labor Relations Review 42:89-99.

Kalleberg, Arne L. 2009. “2008 American Sociological Association Presidential Address: Precarious Work, Insecure Workers: Employment Relations in Transition." American Sociological Review 74:1-22.

Katz, Arnold. 1974. "Schooling, Age, and Length of Unemployment." Industrial and Labor Relations Review 27(4):597-605.

Koeber, Charles and David W. Wright. 2001. "W/age Bias in Worker Displacement: How Industrial Structure Shapes the Job Loss and Earnings Decline of Older American Workers." Journal of Socio-Economics 30:343-352.

Kposowa, Augustine J. 2001. "Unemployment and Suicide: A Cohort Analysis of Social Factors Predicting Suicide in the US National Longitudinal Mortality Study." Psychological Medicine 31:127-138.

Lippmann, Stephen. 2008. "Rethinking Risk in the New Economy: Age and Cohort Effects on Unemployment and Re-employment.” Human Relations 61(9):1259-1292.

Loretto, Wendy and Phil White. 2006. "Employers' Attitudes, Practices and Policies towards Older Workers.” Human Resource Management Journal 16(3):313-330.

McLeod, Jane, Edward Lawler, and Michael Schwalbe, eds. 2014. Handbook of the Social Psychology of Inequality. New York: Springer.

Neumark, David, ed. 2000. On the Job: Is Long-Term Employment a Thing of the Past? New York: Russell Sage Foundation.

Ng, Thomas W. H. and Daniel C. Feldman. 2008. "The Relationship of Age to Ten Dimensions of Job Performance.” Journal of Applied Psychology 93(2):392-423.

Nielsen, Laura Beth, and Robert L. Nelson. 2005. "Rights Realized? An Empirical Analysis of Employment Discrimination Litigation as a Claiming System." Wisconsin Law Review 2005(2):663-711.

Posthuma, Richard A. and Michael C. Campion. 2009. “Age Stereotypes in the Workplace: Common Stereotypes, Moderators, and Future Research Directions" Journal of Management 35(1):158-188.

Quadagno, Jill. 1999. "Creating a Capital Investment Welfare State: The New American Exceptionalism: 1998.” American Sociological Review64(1):1-11. 
Rhodes, Susan R. 1983. “Age-Related Differences in Work Attitudes and Behavior: A Review and Conceptual Analysis.” Psychological Bulletin 93(2):328-367.

Roscigno, Vincent J. 2007. The Face of Discrimination: How Race and Gender Impact Work and Home Lives. Lanham, MD: Rowman \& Littlefield. . 2010. "Ageism in the American Workplace." Contexts 9(1):16-21.

Roscigno, Vincent J., Sherry Mong, Reginald Byron, and Griff Tester. 2007. “Age Discrimination, Social Closure and Employment.” Social Forces 86(1):313-334.

Rosen, Benson and Thomas H. Jerdee. 1976. "The Nature of Job-related Age Stereotypes." Journal of Applied Psychology 61:180-183.

Rothenberg, Jessica Z. and Daniel S. Gardner. 2011. "Protecting Older Workers: The Failure of the Age Discrimination in Employment Act of 1967." Journal of Sociology \& Social Welfare 38(1):9-30.

Rutherglen, George. 1995. "From Race to Age: The Expanding Scope of Employment Discrimination Law." The Journal of Legal Studies 24(2):491-521.

Sandell, Steven H. 1987. The Problem Isn't Age: Work and Older Americans. New York: Praeger.

Schrank, Harris T. and Joan M. Waring. 1989. "Older Workers: Ambivalence and Interventions." Annals of the American Academy of Political and Social Sciences 503(1):113-126.

Scott, Frank A., Mark C. Berger, and John E. Garen. 1995. "Do Health Insurance and Pension Costs Reduce the Job Opportunities of Older Workers?" Industrial and Labor Relations Review 48(4):775-791.

Sharone, Ofer. 2013. Flawed System/Flawed Self: Job Searching and Unemployment Experiences. Chicago, IL: University of Chicago Press.

Smith, Brian T. and Beth A. Rubin. 1997. "From Displacement to Reemployment: Job Acquisition in the Flexible Economy.” Social Science Research 26:292-308.

Taylor, Mary Anne and Holly A. Geldhauser. 2007. "Low-income Older Workers.” Pp. 25-50 in Aging and Work in the 21 st Century. Edited by Kenneth S. Shultz and Gary A. Adams. Mahwah, NJ: Lawrence Erlbaum Associates, Inc.

U.S. Department of Labor, Bureau of Labor Statistics. 2012. Employment Projections-2010-20. Retrieved June 20, 2013 (http://www.bls.gov/news.release/pdf/ecopro.pdf).

Warr, Peter and Paul Jackson. 1984. "Men without Jobs: Some Correlates of Age and Length of Unemployment." Journal of Occupational Psychology 57:77-85. 
Table 1. Demographic Composition of Sample

\begin{tabular}{|c|c|c|}
\hline Characteristic & Count & Percent \\
\hline \multicolumn{3}{|l|}{ Gender } \\
\hline Male & 25 & $48 \%$ \\
\hline Female & 27 & $52 \%$ \\
\hline \multicolumn{3}{|l|}{ Race/Ethnicity } \\
\hline White, non-Hispanic & 30 & $58 \%$ \\
\hline Black & 22 & $42 \%$ \\
\hline \multicolumn{3}{|l|}{ Occupation } \\
\hline Mgmt. \& Professional & 34 & $65 \%$ \\
\hline Skilled & 4 & $8 \%$ \\
\hline Low-wage Service & 14 & $27 \%$ \\
\hline
\end{tabular}


Figure 1. Reemployment of Displaced Workers by Age, 2012

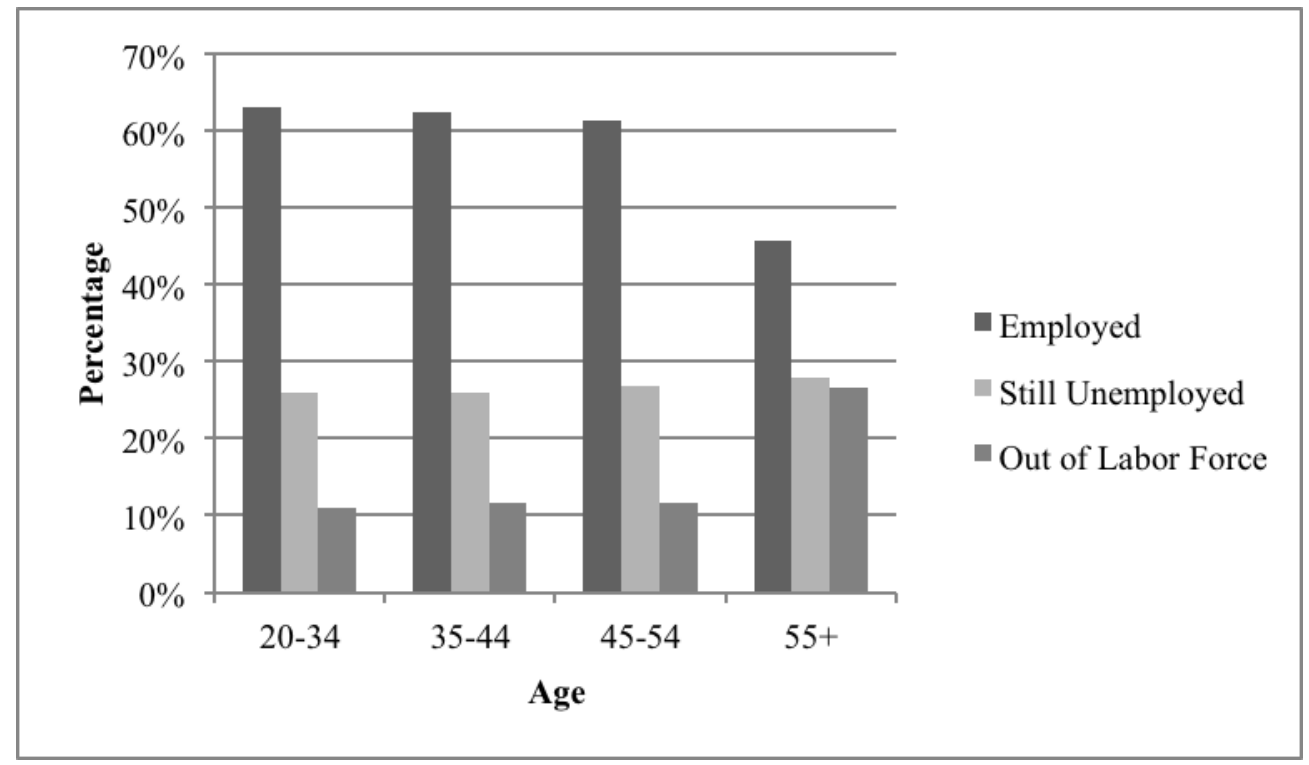

Source: Bureau of Labor Statistics 